\section{PREVENTING WAYS OF ACUTE POISONING IN CHILDREN}

S M Ganieva, A I Iskandarov*, M 0 Abdurahmanova Correspondence: Tashkent Pediatric Medical Institute, Bogishamol Street, Tashkent 223 100140, Uzbekistan

10.1136/ip.2010.029215.29

Among evils, bringing children by civilisation and technical progress for the last decades, especially significant are traumas and poisoning. The aim of study is carry out of quantitative diagnostics criteria and evaluation severity degree of chemical traumas in children and recommendations on their prevention. Material for study were 62 cases of acute poisoning among children at the age from 5 months to 18 years by the most wide-spread poisons: industrial ones dichlorethan, acetic acid; domestic are $\mathrm{PhOI}$ compounds (carbophos, chlorophosis), medicines soporifics from the group of barbituric acid (Phenobarbital). More often the poisonings take place at the age under 5 years old; in our study the poisonings at this age were $72.6 \%$. It is explained by large inquisitiveness and activity of early and preschool age children. Very dangerous age is from 1 to 3 years, the poisonings at this age were $59.7 \%$ in our observations. The second little peak is observed at the age 12-14 years. It is explained by more frequent attempts of suicide in pubertal period. Among poisoned boys were more $67.7 \%$ cases than girls were $32.3 \%$. This fact can be explained by higher activity of boys young and preschool age, their big inquisitiveness and inclination to adventures. Thus, the main ways of preventing acute poisonings in children are: creating intellectual computer system on base of toxicometric researches; creating electron database in toxicology; creating International informative toxicologic centre; instructive work among parents; put scientific working-outs on toxicology into practice. 